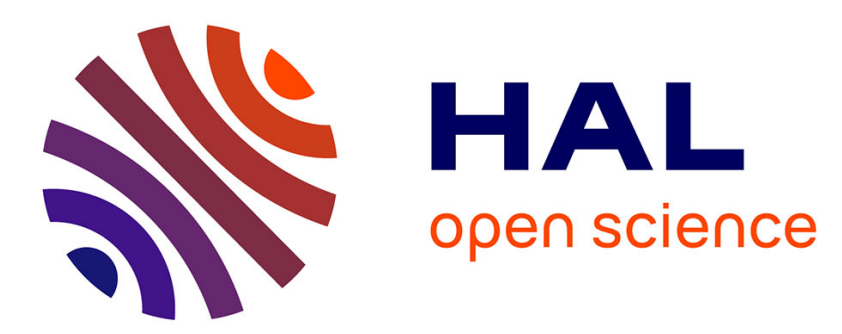

\title{
Turning a graphical method of evidential reasoning into an operational tool for judges? Empirical evidence
}

Olivier Leclerc, Etienne Vergès, Géraldine Vial

\section{To cite this version:}

Olivier Leclerc, Etienne Vergès, Géraldine Vial. Turning a graphical method of evidential reasoning into an operational tool for judges? Empirical evidence. International Journal of Evidence and Proof, 2022, 26 (2), pp.136-156. 10.1177/13657127221076172 . hal-03560219

\section{HAL Id: hal-03560219 \\ https://hal.science/hal-03560219}

Submitted on 9 Feb 2022

HAL is a multi-disciplinary open access archive for the deposit and dissemination of scientific research documents, whether they are published or not. The documents may come from teaching and research institutions in France or abroad, or from public or private research centers.
L'archive ouverte pluridisciplinaire $\mathbf{H A L}$, est destinée au dépôt et à la diffusion de documents scientifiques de niveau recherche, publiés ou non, émanant des établissements d'enseignement et de recherche français ou étrangers, des laboratoires publics ou privés. 


\title{
Turning a graphical method of evidential reasoning into an operational tool for judges? Empirical evidence
}

\author{
Olivier Leclerc, CNRS, Centre de théorie et analyse du droit (CTAD), Université Paris \\ Nanterre (France) \\ Etienne Vergès, Université Grenoble Alpes (France) \\ Géraldine Vial, Université Grenoble Alpes (France) \\ Published in: The International Journal of Evidence \\ \& Proof \\ Online first: 07 Feb. 2022 \\ DOI: https://doi.org/10.1177/13657127221076172
}

Corresponding author: Olivier Leclerc, CTAD UMR 7074, Université Paris Nanterre, 200 avenue de la République, 92001 Nanterre Cedex, France. olivier.leclerc@,cnrs.fr

\begin{abstract}
Research on graphical methods of reasoning has made enormous progress since the pioneering work of Wigmore in the early 20th century and its later rediscovery in the 1980s. While the usefulness of graphical methods for student training and research is widely acknowledged, their use by judges remains marginal, if not nonexistent, even though this was Wigmore's objective. This article explores the difficulties that graphical methods of reasoning must overcome if they are to be integrated into the practice of the courts, at a time when courts are faced with ever more pressing imperatives of efficiency. The research is based on a partnership with the French School of Magistrates (Ecole Nationale de la Magistrature) and is informed by training courses given to magistrates on the basis of real cases, during which the authors proposed that they implement what we have called the Orderly Method of Evidence Analysis. Although the research confirms the value of graphical methods in promoting rigour in evidential reasoning, it also reaffirms the already clearly identified limits related to their complexity and time-consuming nature. The article also points out the difficulties that still need to be overcome in order to operationalise graphical methods of evidential reasoning, and the difficulties encountered by these methods in avoiding judgment bias.
\end{abstract}

Keywords: J. H. Wigmore; Evidential reasoning; French law of evidence;

Diagramming schemes; Chart method 


\section{Introduction}

Wigmore's chart method is the first attempt to link a method of reasoning with masses of mixed evidence to a theory of evidence. Formulated in 1913, it reflects Wigmore's ambition to contribute to the development of a science of proof which would bring the analysis of evidence out of a pre-scientific phase in which it was not systematised but left to professional know-how. In order to "rationally determine the net persuasive effect of a mixed mass of evidence" (Wigmore, 1913, 747), judges and lawyers need, he asserted, a tool for the rational analysis of evidence. To this end, Wigmore proposed to list the available evidential facts (Evidence List) and to identify the subfinal facts, from which it would be possible to decide whether or not the ultimate fact (or probandum) is proven. For this purpose, Wigmore drew up a graphic representation of the evidential facts derived from testimonial and circumstantial evidence, the provisional credit given to them by the person making the chart, the inferences drawn from each piece of evidence, the conviction attached to them, and their probative effect. By means of a rich symbology, these charts rationally order a large amount of evidence that the charter's mind could not immediately grasp as a whole. The method does not command what conclusion is to be reached, but should help to represent clearly the reasoning that is followed. Ambitious and innovative in its time, Wigmore's aspiration to forge a novum organum for the study of evidence in court contrasts sharply with William Twining's sweeping observation that Wigmore's proposal was merely a 'lead balloon' (Twining, 1985, p. 164). This observation is widely shared by scholars of evidence law. It is based on the fact that Wigmore's chart method was barely taken up by scholars of evidence law and has been taught only marginally in universities, even during Wigmore's lifetime. Worse still, there is no indication that the judges for whom the method was intended ever relied on it to improve their professional practice.

However, Wigmore's chart method has never ceased to attract interest, extending far beyond specialists in the law of evidence. In the 1980s the intelligence community saw it as an effective tool for analysing complex situations, where the analyst must take into account and put into order a large number of elements of assessment (Schum, 1987). Anderson and Twining in turn reinvested in Wigmore's chart method and became 'the most active evangelists' (Vignaux and Robertson, 1992, p. 94). Anderson and Twining, joined by Schum, extensively recast the method, simplifying its presentation and the symbols used (Anderson and Twining, 1991; Anderson, Schum, and Twining, 2005).

Wigmore's chart method has also been explored by scholars of argumentation theory who have sought to describe judicial reasoning by a diagramming scheme (Walton, 2005; Tillers, 2007; Walton, Reed, and Macagno, 2008). Wigmore from this perspective appeared as a lesser known precursor of argument diagramming (Vignaux and Robertson, 1992, p. 96; Rowe and Reed, 2006), relevant for analysing the particular context of legal evidence where argumentation is conducted between two actors 
(lawyers, judges) who respond to each other. Thus the description of the pattern of an argument proposed by Toulmin (2003 [1958] 92 sq.) has much in common with the fundamental operations identified by Wigmore and with the basic principles of his graphical formalisation. Both symbolise by an arrow the link between a claim and the data that supports it (Nance, 2007). Similarly, Toulmin's warrants and rebuttals echo Wigmore's distinction between the facts that can corroborate or explain away an inference. And although Wigmore was obviously unable to imagine such a development, since it would come much later, his pioneering contribution to argument diagramming and assessment has also been debated by informal logic and argumentation diagramming scholars. Goodwin (2000) argued that Wigmore's rhetorical orientation to argument diagramming ameliorates some of the difficulties of evaluating arguments in tree diagrams. Wigmore's graphical method has not been simply repeated, but has been the subject of multiple reappropriations, simplifications and additions, so as to include temporal analysis (Tillers and Schum, 1988), contribute to defeasible logic (Verheij, 2000; Bex et al., 2003), and estimate the weight of the ultimate probandum (Chalamish, Gabbay, and Schild, 2011). But Wigmore's proposal has also been progressively challenged by the development of probabilistic networks, whether in influence networks or, even more so, Bayesian networks (Vignaux and Robertson, 1992; Kadane and Schum, 1996; Hepler, Dawid, and Leucari, 2007; Kjærulff and Madsen, 2008; Dawid, Schum, and Hepler, 2011).

As Twining had anticipated, ${ }^{1}$ the development of cognitive agents (Tecuci et al., 2016) has renewed interest in Wigmore's chart method, since, by providing a structure for the ordering of reasoning, the method helped prepare the ground for its automation by software (Vignaux and Robertson, 1992; Bex et al., 2003). Building on this, it has been proposed that human users could be assisted in the creation of an evidence diagram by means of an algorithm aiming at semi-automatically transforming an evidence list into a Wigmore chart (Chalamish, Hazzom, and Schild, 2013). Similarly, several software packages have been developed to assist in the visualisation of argumentation schemes, Araucaria (Reed and Rowe, 2004; Reed and Rowe, 2007), Carneades (Gordon, 2007; Gordon, Prakkan, and Walton, 2007), ArguMed (Verheij, 2005), and Rationale (van Gelder, 2007) being the best known.

Given that the theory of reasoning and informal logic have made huge advances since Wigmore, is the interest of his views now only historical? This question goes back to Wigmore's original purpose, which was to provide trial practitioners with a tool to assist in the analysis of evidence. If there is one point on which Wigmore's chart method can be called a 'lead balloon', it is its operational character. The usefulness of Wigmore's method for student training and research is indeed recognised (Robertson, 1990; Reed and Rowe, 2004; Rowe et al., 2006); but can it be useful to judges in assessing evidence and to lawyers in building their case? Do contemporary developments in judicial practice still allow for the implementation of the Wigmore chart method?

1 "It seems quite possible that Wigmore's method will come into its own in the computer age" (Twining, $1985,135)$. 
The value of Wigmore's chart method for judges is regularly affirmed (Anderson, Schum, and Twining, 2005; Robertson, 1990; McDermott, 2015); yet its complexity and the tedium of its implementation have been highlighted repeatedly by virtually all of Wigmore's readers (Twining, 1985; Robertson, 1990; Goodwin, 2000; McDermott, 2015). The chart method is particularly time-consuming when used to conduct a macro-analysis of all available evidence, the primary function that Wigmore envisaged for it, yet remains demanding when applied to only part of the evidence. The heaviness and complexity of the work required does not go well with the diffusion in courts of imperatives of efficiency imposed by managerial tools stemming from New Public Management (Adler, 2003; Hodgson and Roberts, 2010; Rothmayr Allison, 2013). In France, judges are nowadays evaluated according to indicators such as the 'coverage rate' (ratio between the number of cases registered and the number of cases settled) [Cour de cassation, 2012, 507] or the 'average age of the stock' (average time for processing pending cases) [Chambaz, 2020, 7]. Wigmore's chart method seems to be designed for a judge who has time to deal with complex cases; much less so for a judge subject to performance indicators and faced with mass litigation. Moreover, the expansion of the use of electronic evidence confronts judges with such volumes of material that the challenge for them is not so much to provide an exhaustive graphical representation, as Wigmore proposed, as to deploy mining tools enabling them to identify in the mass of evidence those facts that are sufficiently relevant to be taken into account (Gogolin, 2010; Quick and Raymond Choo, 2014; Brady, Overill, and Keppens, 2014).

This paper intends to test the usefulness of graphical methods of evidential reasoning for judges, taking into account as closely as possible their actual working conditions. Starting from the idea that diagramming schemes have a role to play in the analysis of evidence in all legal systems, that they are useful tools to help decision making, and that, paradoxically, they have not received the success that could be expected in the judiciary, this article asks the question of whether they can become practical methods of evidence analysis.

However, the usefulness of diagramming is most often assessed without involving the judges themselves. This leads to a paradox. Wigmore presented his chart as a tool to guide judges' reasoning in reaching a decision. But the examples he gave (Commonwealth v. Umilian, 1901; Hatchett v. Commonwealth, 1882) were all based on court decisions already rendered. The same is true of authors who have subsequently defended the interest of his method, either by relying on recently decided cases (the Arthur Allan Thomas case in New Zealand: Robertson, 1990; the Gatete trial before the International Criminal Tribunal for Rwanda: McDermott, 2015), or even more often on a cause célèbre such as the 1920s Sacco and Vanzetti case (Kadane and Schum, 1996; Reed and Rowe, 2007). These analyses are therefore based on the motivation for the court decision and offer a retrospective reading of the evidence. As Robertson (1990) acknowledges, the analysis is more about those evidential sources rather than about the case itself. Moreover, all the analyses produced on Wigmore's chart method are illustrated by court decisions from common law countries where the motivation for the 
court decision is often much more detailed than in civil law countries (Dawson, 1968; Markesinis, 1994; Lasser, 2005; Brunet, Halpérin, and Nollez-Goldbach, 2015).

To avoid these shortcomings, this article makes three original contributions. Firstly, we have carried out conceptual work to construct a graphical method inspired by Wigmore's that is, on the one hand, adapted to French criminal procedure and to the context of civil law countries more broadly considered; and, on the other hand, sufficiently simplified to be taught in the context of professional training for judges. This method is referred to as the "Orderly Method of Evidence Analysis". Secondly, we have constructed a research protocol based on original and complete court files, as they are in the hands of judges when they prepare their decisions, and we have worked on these real files with practising judges. Thirdly, we have analysed the difficulties encountered by judges in implementing our graphical method and identified the main obstacles to the operational use of a graphical method of evidence analysis in actual judicial activity, beyond the well-known argument of its complexity. Section 1 describes the research protocol that was conducted and the two cases that the judges worked with. Section 2 describes the Orderly Method of Evidence Analysis that we have designed based on Wigmore's chart method and that we have adapted to French criminal procedure. Section 3 assesses the benefits and difficulties encountered by judges during work sessions on real cases. This article concludes with critical insights into the operational implementation of diagramming schemes in the context of contemporary court functioning and identifies the challenges that such methods must overcome if they are to be meaningful for judges.

\section{Section 1. Research protocol and presentation of the 'Lambert' and 'Caro' cases}

The research presented in this article was conducted as part of a collaboration between the three authors and the French Ecole Nationale de la Magistrature. In France, judges are state officials, and their training is centralised by the Ecole Nationale de la Magistrature, which maintains a common culture through the training of intending judges and the continuing education of sitting judges. The training provided at the Ecole Nationale de la Magistrature aims to give judges the operational tools of their profession, and not just to teach them the law, which is already largely covered by the law degree they must have obtained previously at university. Thus, while the Ecole Nationale de la Magistrature is a relevant entry point for disseminating a better culture of evidential reasoning among practising magistrates in France, the teaching cannot be purely theoretical. In this research, therefore, we have treated graphical reasoning methods as tools that magistrates can actually use to construct their judgements and not only to retrospectively analyse a case that has already been decided. 


\section{Research protocol}

The research was conducted over two years (2018-2020) and followed a protocol in three stages.

In the first phase, the partners endeavoured to isolate complex criminal cases that were marked by uncertainty about the course of events and the guilt of the suspect and which involved large masses of evidence. Two cases were selected, and for each of them we were granted access to the entire procedural file and evidence as well as to the sentences that had been issued by the courts in these cases at first instance and on appeal. This case selection phase was complemented by a research visit to the Ecole Nationale de la Magistrature to learn how the evaluation of evidence and the drafting of judgements are taught to student magistrates.

Secondly, based on close examination of the two selected case files, we devised a graphical method of analysing evidence derived from Wigmore's chart method, with the intention of making it as operational as possible. We labeled it the "Ordered Method of Evidence Analysis". To this end, it was necessary to adjust Wigmore's chart method. Firstly, like Anderson and Twining (1991), we modified the symbols used and reduced their number. Secondly, as this work was the first attempt to use a graphical method of evidential reasoning in France, we had to take into account the procedural context specific to this country. France is indeed a civil law country. Its criminal procedure is mainly inquisitorial and its civil procedure adversarial, albeit that this distinction has become less and less clear in recent times (Vergès, 2007). French evidence law also differs from common law countries in that evidence is dealt with in a written file, accessible to lawyers and judges before the trial. Evidence is not therefore presented exclusively orally and during the trial (Damaška 1997). Finally, French law does not distinguish, as Wigmore did, between testimonial and circumstantial evidence. Having developed this new graphical method, we implemented it to analyse and graphically represent the two selected cases.

Thirdly, we designed a training programme for judges in continuing education, as part of the training they receive at the Ecole Nationale de la Magistrature. The training sessions were aimed at professional magistrates from the Lyon and Grenoble Courts of appeal (15 participants) and were designed in consultation with the magistrates responsible for training in these appeal courts. Before the training session, held in Lyon in September 2019, each participant was handed the file of the first case (Lambert case) and was asked to decide the case (is the person prosecuted guilty or not guilty?). During the session, we were able to use this case to teach magistrates the Orderly Method of Evidence Analysis. This first training session, and the feedback we received from the magistrates, then allowed us to adjust some aspects of the method. In November 2019, during a second training session held in Grenoble, the same magistrates were asked to study the second criminal case (Caro case) and to implement our graphical method to analyse the evidence. At the end of the two days session, a questionnaire was returned to all magistrates who had attended the training to ask them 
to evaluate the implementation of the graphical method. The evaluation was complemented by debriefing sessions at the end of each day of training.

\section{Presentation of the 'Lambert' and 'Caro' cases}

The two criminal cases on which we worked with magistrates involve the following circumstances (the names of the parties have been changed).

The Lambert case relates to an offence of intentional violence. A victim was stabbed several times late in the evening by a person he said he saw and identified as his neighbour, Mr Lambert, who lived in the same building a few floors below. The suspect denied the facts. No one, apart from the victim, saw the assailant. The victim had taken drugs during the evening. Furthermore, the victim could not explain why he was assaulted and the motive for the crime was therefore unknown. The suspect himself, $\mathrm{Mr}$ Lambert, was severely drunk that evening. Mr Lambert is a habitual offender. He has several convictions for property offences. At the time of his trial by the Grenoble criminal court, he was in prison due to another conviction. Interestingly, the file contains a wide range of evidence: the victim's accusation, the suspect's denials, testimonies, geolocation records from the suspect's mobile phone, DNA analysis from blood traces found in different places, multiple police observations. During the night of the crime, Mr Lambert behaved suspiciously. At 1 a.m., when police officers called to the scene went to his place, he had just mopped the floor. The police suspected that he had wanted to remove traces of blood, but the forensic test with 'Bluestar' (a product that detects removed blood) turned out to be negative. Faced with contradictory evidence, Mr Lambert was convicted by the criminal court. However, on appeal, the Court of Appeal acquitted him. The magistrates attending the training sessions were also divided. Two thirds believed that Mr Lambert was guilty. One third thought that the evidence was insufficient to convict him. The Lambert case is thus typically a complex case that is marked by uncertainty.

The Caro case involves the theft of a luxury watch worth $€ 30,000$ from a hotel room. The suspect was a chambermaid, Ms Caro. A videotape showed her entering the room of the victim for no apparent reason during the day for a short time. The file contains a variety of evidence, including CCTV footage from the hotel (with date and time stamp) and data extracts from the suspect's mobile phone. The consultation of Ms Caro's mobile phone by the police returned that she had been surfing web pages with pictures of the exact same model as the one that had been stolen. Moreover, the 19-yearold maid's mobile phone showed almost no text messages, which led the police to suspect that she had recently deleted her conversations. Nevertheless, Ms. Caro denied having committed the theft and no evidence was found that she had been in possession of the watch. A police search of her home did not succeed in finding the object either, and the watch could never be found. The Caro case is used regularly at the Ecole Nationale de la Magistrature to train student magistrates in drafting criminal judgements. It was therefore interesting for us to use the same case, which is well known to students and training magistrates, to study evidential reasoning. A survey we 
conducted on the maid's guilt found that magistrates were divided in their assessment of the case and that their views heavily depended on their professional experience. Of the intending judges surveyed in November 2018, 60\% thought she was guilty and $40 \%$ thought her not guilty because of a lack of evidence. In contrast, the serving magistrates interviewed in November 2019, including the judge who had actually tried the case that we interviewed separately, all believed Ms Caro was guilty.

\section{Section 2. Description of the Orderly Method of Evidence Analysis}

Derived from Wigmore's chart method, the Orderly Method of Evidence Analysis is designed to analyse files containing large masses of evidence. The main principles are as follow: rendering the elements of the case as completely as possible; dividing evidential reasoning into several stages in order to move progressively from a large mass of evidence to a smaller number of facts; grouping the facts into blocks in order to reduce the units from which the judges forge their convictions; clarifying the way in which one moves from one piece of evidence (or one fact) to another piece of evidence (or another fact) by means of inferences; linking the elements together (elements that corroborate, contradict, or neutralise each other); and representing the case visually to make it easier to reach a conviction. The graph represents the whole case in an orderly fashion and allows judges to see "at a glance" the facts that they consider decisive. The Orderly Method of Evidence Analysis also shares with Wigmore's chart method two analysis tools, although each is substantially amended: a summary list presenting the evidence, the facts derived from it, and the conviction reached by the judge during the analysis of the case (1), and a chart that represents by symbols the articulation of all the elements described in the summary list (2).

\section{The summary list}

Drafting a summary list is the first step in the Orderly Method of Evidence Analysis. It consists of a list of different pieces of information that enter the evidential reasoning process. This information derives first of all from the case file: facts (e.g. the defendant did not have a weapon), evidence that supports these facts (e.g. testimony). In addition, the list indicates the value the person making the chart (the 'charter') places on the facts and evidence (e.g. the testimony is unreliable because the witness contradicts himself). Eventually, the list will also contain the generalisations that the judge introduces into the reasoning. Drawing up the summary list is a long and possibly tedious process; however, it deserves care and attention as it is intended to ensure that no fact or piece of evidence is overlooked. The summary list is developed in three stages: first it is compiled, then it is organised, and finally it is supplemented by subjective elements reflecting the charter's own convictions.

In order to compile a list of the information to be retained, the file must first be read carefully. In a system where, as in France, the evidence is recorded in a written file, 
which can be very voluminous, this stage is the longest. In the course of the reading, it is necessary to note down, in successive lines, all the facts that emerge from the file and the pieces of evidence associated with them. Each line of the summary list should have a number that will later allow the information in the line to be linked to the chart.

Example (Lambert case):

\section{THERE IS NO DISPUTE BETWEEN THE VICTIM AND THE SUSPECT}

2. Hearing of a witness: the witness is not aware of any dispute between the victim and the defendant

3. Hearing of the victim: the victim indicates that there is no dispute between him and the defendant

4. Hearing of the defendant (Lambert): he confirms he had no dispute with the victim

The fact in line 1 is supported by three pieces of evidence (lines 2-4). At this point, the summary list contains all the information in the file, in the order in which the file was read. The information is not grouped in any relevant way.

The next step is to organise the items of the list. The aim is to group the information and prioritise the different lines of the list to reach a three-level organisation. At the first level are the pieces of evidence recorded in the file (e.g. a record, testimony, a photograph) from which an evidential fact is derived. At the second level of this organisation are the "relevant facts" (in bold in the examples) that derive from the evidence. The "relevant facts" (i.e. the factum probans) correspond to what Wigmore refers to as the evidential facts (inferred from individual pieces of evidence), and Anderson, Schum, and Twining refer to as "intermediate probanda" (2005, p. 126). The relevant facts in turn support the existence or non-existence of a "decisive fact", which we define as essential facts that the judge must take into account in forming a final conviction (these facts are shown in bold capital letters in the examples). These are what Wigmore calls "subfinal facts" (1913, p. 755) and Anderson, Schum, and Twining "penultimate probanda" (2005, p. 126). Based on these elements, the charter forms a conviction about the fact to be proven, i.e. the probandum, "the ultimate fact in issue" (Wigmore, 1913, p. 756), "the ultimate probanda" (Anderson, Schum, and Twining, 2005 , p. 132). Although our method is conceptually aligned with these authors, its vocabulary is distinct. The primary reason for this is pedagogical. The formulas "penultimate", "subfinal", and probandum have been proven to arouse a sense of incomprehension on the part of the judges; moreover, in French law the use of the concept of relevance does not correspond exactly to that of Anglo-American law (Vergès, Vial, and Leclerc, 2015, p. 161). From the perspective of making a diagramming scheme operational, it is crucial to ensure that the vocabulary used is well received.

Example (Lambert case):

1. THE DEFENDANT HAD NO WEAPONS (DECISIVE FACT)

2. The defendant (Lambert) generally does not carry a weapon (relevant fact)

3. Hearing of a cousin hosting the defendant: to his knowledge, the defendant does not possess a knife (evidence)

4. Hearing of the defendant: he has not carried a weapon for a long time (evidence)

5. No weapon is found where the defendant sleeps (relevant fact)

6. Minutes of police home visit (evidence) 
In this example, the decisive fact that the defendant did not possess a weapon (in bold capital letters) is supported by two separate relevant facts (in bold), which are in turn supported by one or more pieces of evidence.

As facts are not decisive by nature, their identification is key. This will inevitably vary from one reader of the file to another, depending on whether the analysis is conducted by a judge, a prosecutor, or a lawyer for one of the parties. This observation is consistent with Anderson, Schum, and Twining's (2005, p. 124) comment on the importance of clarifying the standpoint. The differences that may arise between the parties, or between a party and the judge, in the choice of decisive facts is indicative of the fact that, as Wigmore observed, graphical representations can be used to represent a person's reasoning, and thus to ascertain its soundness, but they are not intended to be a tool for showing with certainty "what our belief ought to be" (Wigmore, 1913, p. 749). If several judges examine the case, they may compare their views and possibly agree on a shared list of decisive facts.

In order to identify the decisive facts, it is necessary to group them together. After going through all the elements of the file, the judge must group certain facts together and suggest the existence of a decisive fact. For example, in the Caro case, several relevant facts converged to show that the defendant tried to erase the traces of the offence: the police found only four text messages in the suspect's mobile phone, all posterior to the theft of the watch; the defendant acknowledged to the police that she had exchanged several text messages which did not appear in the phone; the defendant stated during her hearing that she had not deleted her SMS history. These facts converge to the decisive fact that the defendant tried to erase the traces of the offence. When reading through the list, it is therefore necessary to intuitively group together information that tends to demonstrate the same facts, thus forming blocks. "Catenate inferences" (Wigmore, 1937, p. 13) hence link one or more pieces of evidence, one or more relevant facts, and a decisive fact that must be taken into account in order to decide the existence of the fact to be proven (the maid stole the watch). Sometimes the evidence leads directly to a decisive fact without any intermediate relevant fact. The chain is then limited to the piece of evidence and the decisive fact.

The number of decisive facts is not known in advance. Two pitfalls must be avoided. The first is to select too few decisive facts and to omit elements of the case. Where this appears to have happened, this may be an indication that the file itself is incomplete. The second difficulty is to select too many decisive facts and then to fail to overcome the complexity of the case. In the light of our experience with the training of judges, a range of between 5 and 10 decisive facts seems to be appropriate. This may vary due to the complexity of the case, the number of defendants, the number of victims, and the diversity of the evidence. The identification of the decisive facts is important, but so is their formulation. The decisive facts are not readily formulated in the file and the reader must find the most appropriate formulation. This formulation necessarily impacts the orientation of the conviction of the judge who has to try these facts, as we will discuss below.

When all the facts (supported by evidence) are grouped under decisive and/or relevant facts and the irrelevant facts are eliminated from the list, the judge can then 
introduce additional elements that express his or her provisional belief, consisting in both inferences to new facts and conviction marks.

Example (Lambert case):

\section{THE DEFENDANT HAD A CULPABLE ATTITUDE AFTER THE INJURIES} (DECISIVE FACT)

2.The defendant ran upstairs in the building at a late hour (relevant fact)

3.A neighbour states that he saw the defendant, at around 1 a.m., run upstairs and quickly return home (evidence)

4. $\quad$ T The fact that a person runs upstairs in a building at this late hour of the night and quickly returns home suggests that the person had something to hide

In this example, the judge induces a new fact resulting from a generalisation, i.e. the application of a general rule to the observation of a particular fact: if a person runs up a staircase shortly after an attack, this usually indicates a flight on their part. This subjective assessment may result from an induction by generalisation, but also from simple personal conviction, the way the person judging the case represents the world, or, more generally, from any operation of reasoning that this person carries out (Anderson, 1999; Anderson, Schum, and Twining, 2005, p. 266). It may benefit the prosecution, as in this example, or the defence. The information derived from the judge's subjective assessment must be formally differentiated from the other elements of the summary list. We use the symbol at the beginning of the line, as in Wigmore, and write the sentence in italics in the summary list.

The personal conviction of the judge can also be made apparent by the insertion of conviction markers. If he or she considers it useful, the judge who draws up the summary list may add elements expressing his or her belief in the existence or nonexistence of a fact or his or her opinion as to the weight of a piece of evidence. These markers are included in additional rows of the summary list.

Example (Lambert case):

1. > The victim's testimony is unreliable (conviction-reducing)

2. The victim is a drug addict (relevant fact)

3. Victim's hearing: victim states that he has drug problems (evidence)

4. Testimony of the victim's brother: he states that the victim is undergoing medical treatment for drug addiction (evidence)

5. Victim used heroin prior to the medical brigade's intervention (relevant fact)

6. Medical brigade report: victim states that he had used heroin before the fire brigade arrived (evidence)

In line 1, the judge expresses a belief about the reliability of the victim. He or she considers the victim to be unreliable because he is a drug addict (line 2) and used drugs prior to the assault (line 5). The evidence for drug addiction is listed in lines 3, 4, and 6. In this example, the judge considers that the victim's drug addiction reduces his reliability. This assessment is reflected by a conviction "reducer" (represented in the summary list by the symbol $>$ ). The judge may, conversely, believe a piece of evidence has a particular weight and then introduce a conviction "enhancer" (represented in the list by the triangular symbol I $>$ ). 
Example (Lambert case):

I $>1$. The witness is particularly credible because he was able to personally see the facts (conviction amplifier)

2. The witness was standing near the scene of the crime and had a clear view of it (relevant fact)

3. Hearing of the witness describing his position at the time of the offence (evidence)

In this example, the judge considers that the witness's location at the time of the offence strengthens the credibility of his or her testimony. The judge places great confidence in this testimony and therefore gives it a greater probative value. Once all the relevant facts supported by the evidence have been grouped under decisive facts and the judge has added subjective elements relating to his or her conviction (inferences to new facts, reducers, amplifiers), the summary list is considered complete. It is then time to move on to the graphic representation of the case.

\section{Graphical representation}

The graphical representation serves two purposes. Firstly, it aims to articulate the evidence and the facts arising from it, either reinforcing or contradicting each other. Secondly, it allows the mass of information in the file to be grasped "at a glance". The graph visually represents the three-level organisation identified in the summary list and enriches it with the judge's assessment of the evidence and facts.

The Orderly Method of Evidence Analysis uses two main categories of symbols. The first are the "building blocks" of the chart, including the evidence, the facts, and the inferences that lead from the former to the latter, as well as the generalisations. Our symbology departs from Wigmore's by not distinguishing between testimonial and circumstantial evidence: instead, we use two different symbols to represent evidential facts (circles) and pieces of evidence (squares). 


\section{Building blocks}

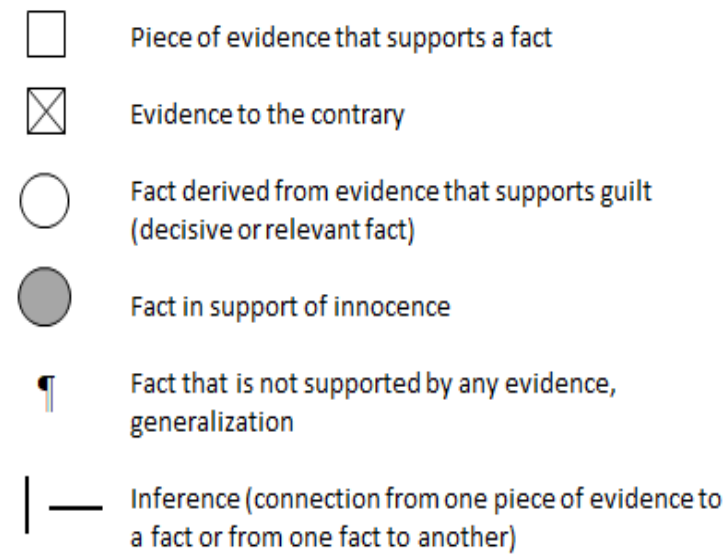

The second category of symbols includes "conviction marks" that express the conviction of the charter.

\section{Conviction marks}

Denotes significant probative value
(strong or very strong)
The probative value of a piece of evidence is
questionable
Strong probative value attached to
evidence that contradicts a fact

The drafting of the graph follows a back-and-forth movement. The first stage starts from the decisive facts and works down to the relevant facts and finally to the evidence. To do so, it is first necessary to draw up a graph of the decisive facts. At the 
top of this chart is the ultimate probandum. In criminal matters, this means questioning the guilt of the person being prosecuted (did Mr Lambert assault the victim? Did Ms Caro steal the watch?). To reach a conviction on guilt, the judge relies on all the decisive facts represented in the graph.

Example of a decisive facts graph (Lambert case):

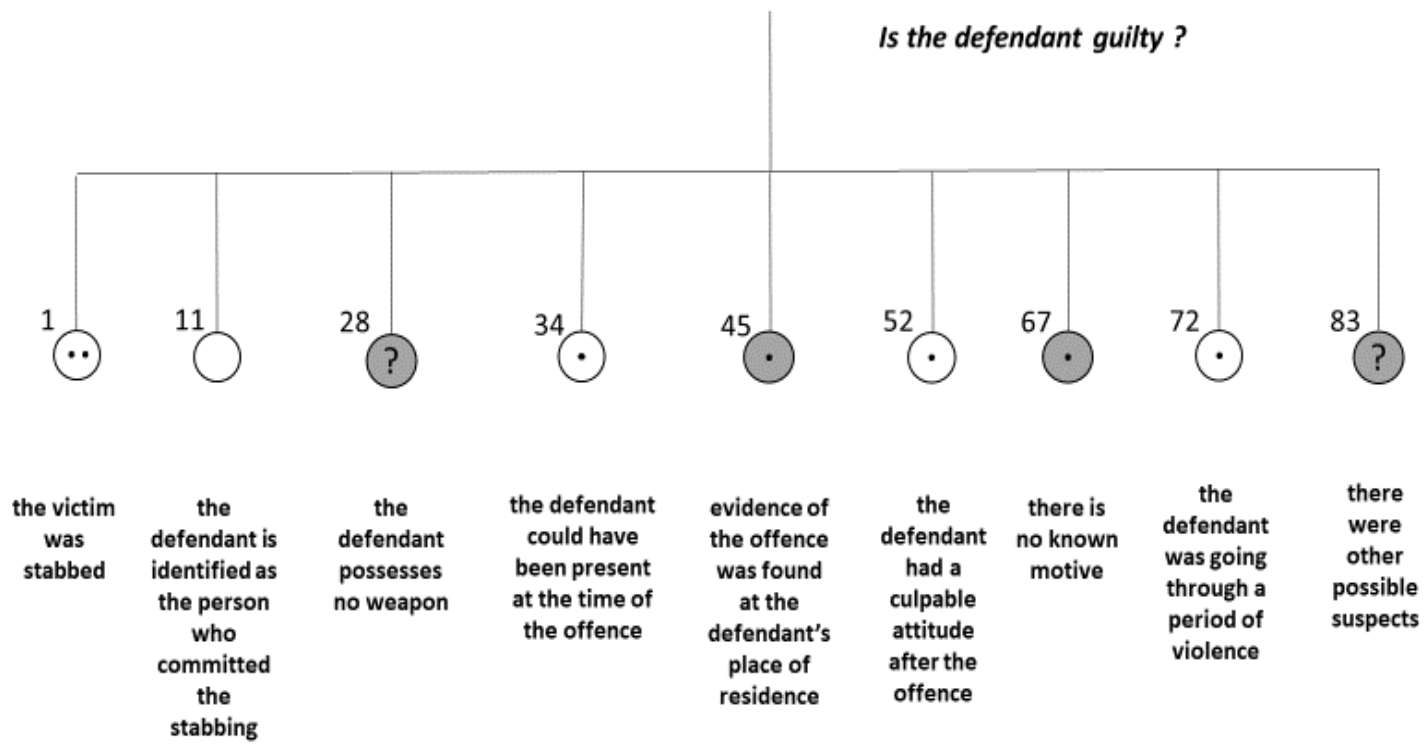

This graph represents the final outline of the Lambert case. In white are the decisive facts in favour of the guilt of the person prosecuted, and in grey those in favour of their innocence. Each decisive fact must be listed and numbered from the number assigned to it in the summary list. At this level of graphing, the decisive facts are not yet associated with conviction marks. Before that, the chart must be continued for each decisive fact, entering the relevant facts and evidence from which it is inferred. 


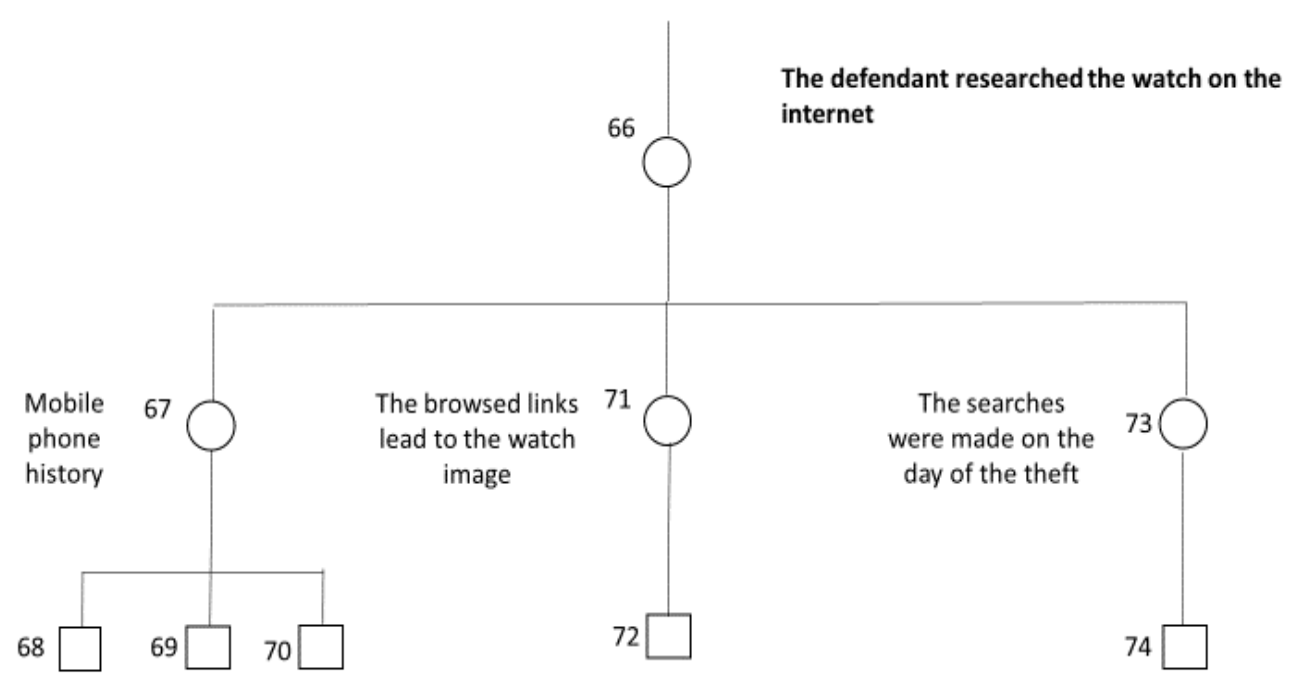

In this graph, the decisive fact is represented by a circle numbered 66 , which corresponds to the number in the summary list. The wording of the decisive fact is also displayed on the graph. On the lower level are listed all the relevant facts (also represented by circles) that support the decisive fact (facts 67, 71, and 73, which are also briefly summarised to make the graph easier to read). Then, on the lowest level, the evidence that supports each fact is represented. Evidence is represented by squares, to visually differentiate it from the facts. There is generally too much evidence for it all to be described by a sentence on the graph. However, each piece of evidence can be easily traced in the summary list by its number.

The Lambert case exhibits a complex tree structure, which presents not only the facts drawn from the evidence but also some of the elements of conviction presented above, namely generalisations, amplifiers, and reducers. In the example below, the question arises as to the attitude of Mr Lambert at a time close to the attack on the victim. The relevant fact concerns the guilty attitude of the defendant and the clues that were found at his place. 


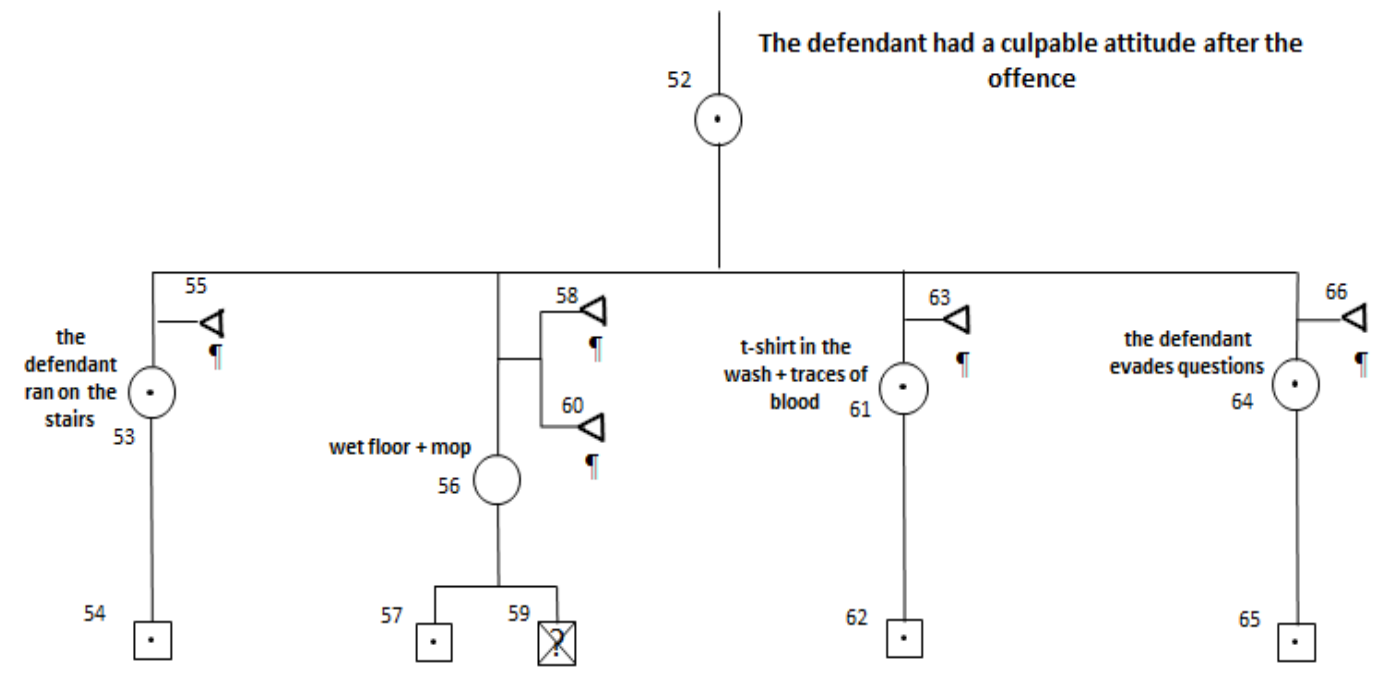

The graph contains several facts relating to the investigation and a few symbols that reflect the assessment of the judge. For example, 56 refers to the fact that investigators discovered a wet floor and mop in the suspect's house in the middle of the night. Here is an excerpt from the summary list about this fact and its interpretation:

56. At 1 a.m. the floor is wet and a bucket and mop that have just been used are on the floor (relevant fact)

\section{Police findings (evidence)}

58. I Mopping the floor at 1 a.m. suggests that the person wanted to remove traces (generalisation)

59. Suspect in custody: He indicates that he did not mop the floor. He also states that the mop is dry (evidence)

60. Denying a fact found by police officers that would be in favour of the prosecution, makes the suspect's attitude even more suspicious (generalisation)

In line 58, the reasoning contains an element of personal conviction. If the suspect did indeed mop the floor at 1 a.m., this suggests that he may have wanted to cover his tracks. This attitude is therefore suspicious. The sign $\uparrow$ symbolises generalisation (see above). It reflects the following reasoning: in general, housework is done during the day. If a violent attack has taken place on the floor above and the suspect mops the floor in the vicinity of the attack, this can be interpreted as an attempt to remove traces. The triangular symbol that accompanies this generalisation in the diagram represents an amplifier, i.e. the fact that the generalisation amplifies the belief that the defendant displayed a guilty attitude at the time of the incident. 
After having descended the levels by introducing relevant facts and evidence, the different levels should then be ascended based on the evidence. This consists of adding degrees of belief at each level of the graph (probative force of the evidence, then conviction relative to the relevant facts, and finally the decisive facts). Like Wigmore, we use two symbols to express the level of conviction: dots and question marks. One dot means that the conviction is strong and two dots that it is very strong. For example, if two pieces of evidence have a high probative value and corroborate each other in support of a relevant fact, the judge displays a strong conviction in favour of this fact (indicated by one or two dots). A question mark means that the conviction is weak. It can also be doubled to indicate a very weak conviction. When no conviction mark is specified, this indicates a neutral conviction.

Example (Caro case):

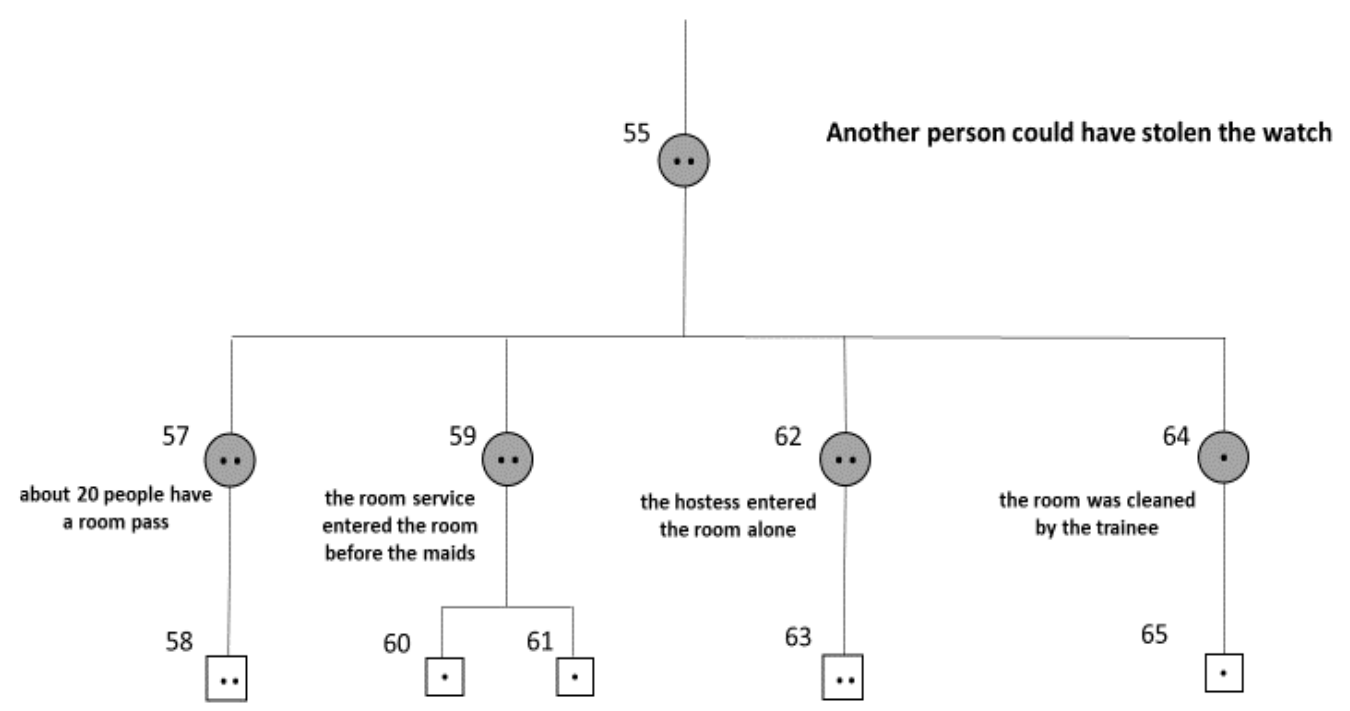

In that graph, the judge is considering the hypothesis that a third person may have stolen the watch. This hypothesis is favourable to the defence. The chart contains evidence that is highly probative $(60,61$ : minutes of the hearing of the maid and one of her colleagues; 65: minutes of the hearing of the defendant in police custody), and even very strong (58: minutes of the hearing of the hotel manager; 63: video recordings). Moreover, some of these pieces of evidence corroborate each other. The facts derived from them are therefore supported by a very strong conviction (two dots) and the person drawing up the graph can thus express a strong conviction with regard to the decisive fact (also with two points). In this scheme, it seems convincing that another person could have stolen the watch.

When a graph has been drawn up for each of the decisive facts, the judge's conviction is ascertained for each of these facts. It then becomes possible to reason with 
decisive facts only and to conclude either that the disputed fact is proven or that it is not. The chart does not dictate the judge's conclusion; it only shows the elements that go into that reasoning and the weight given to each of them. For several reasons, the outcome of the assessment is not automatic: (1) it is not a matter of keeping score or comparing the number of elements in favour of guilt or innocence; (2) it depends on the correlations that the judge establishes between the decisive facts, and indeed in some cases the correlation between two facts may outweigh all the other decisive facts; (3) it differs from one judge to another. For example, when faced with the above chart, one judge may consider that there is sufficient evidence to find the defendant guilty, while another considers that there is sufficient doubt to acquit.

\section{Section 3. Results and discussion}

Our research has allowed us to test the benefits and limitations of our Orderly Method of Evidence Analysis. The outcome is in some respects dependent on the specific features of the French judicial system, but it also provides us with more general conclusions about the use of diagramming schemes in other jurisdictions. The benefits of using a graphical method to support evidential reasoning are amply confirmed (1). Nevertheless, there were also clear indications that these methods face practical limitations when confronted with contemporary judicial practices and the imperatives of cost-effectiveness that are increasingly weighing on the courts (2). Finally, our research has highlighted the limitations of graphical methods for accurately representing evidential reasoning (3).

\section{Contributions of diagramming schemes to the practice of evidential reasoning}

During sessions with judges or trainee magistrates, we observed that judges spontaneously reasoned by accumulating evidence and facts indiscriminately, and then presented these elements in the form of a list of elements in favour of the prosecution or the defence. The use of a diagramming scheme brought out a very different style of reasoning, in which evidence and evidential facts were articulated. As Walton (2009) highlighted, the combination of evidence improves the quality of the reasoning, as it gives a clear view of corroborating and contradictory evidence. For example, in the Caro case, an important question was why the maid entered the room of the owner of the stolen watch in the middle of the day although she had already cleaned it earlier. The maid stated that she had entered the room to close a window that had been left open. The file contained a summary report of the CCTV recordings of the corridor indicating that the maid had spent two minutes in the room. This was much longer than the time needed to close the window, which the investigators estimated at 25 seconds. The summary report thus undermined the suspect's statements. However, another document included in the file listed in detail all the movements captured by the CCTV in the corridor and the exact times they took place. This document suggested that the maid had only been in the room for 18 seconds. Contrary to the summary report, this 
piece of evidence made the maid's explanation plausible. Thus, the study of all evidence available made it possible to contrast the summary report of the CCTV recordings with the detailed document derived from it and to conclude that the latter had a stronger corroborative weight than the former. The diagramming method was then instrumental in establishing a hierarchy between the evidence.

Graphical methods also help to draw attention to the distinction between direct and indirect evidence. Direct evidence is linked to a fact by a single inference; indirect evidence is linked to a fact by a chain of inferences that distances the fact from the evidence. For example, in the Caro case, the police examination of the maid's mobile phone revealed that it contained very few text messages. This fact (few SMS messages) follows directly from the evidence (the mobile phone), but is not relevant to prove the maid's guilt. However, two more facts were stated in the police report: the maid certainly deleted the contents of her mobile phone; this proves that she sought to hide the evidence of her guilt. These two facts were not directly related to any piece of evidence, rather they derived from secondary inferences that involved generalisations. To infer that the mobile phone has been cleaned, it must be assumed that the maid, aged 19 , uses her mobile phone a lot. The fact that the phone was almost empty therefore indicated that the situation was unusual, which allowed the police officer and the judge to conclude that the data on the phone had been wiped. The fact that a suspect erases the content of their communications when suspected of theft thus suggests, by generalisation, that they tried to conceal evidence of guilt. The graphical representation of this reasoning clarifies that from a single piece of evidence (forensic examination of the phone), the police have inferred three facts: (1) the phone is empty, (2) the contents have been discarded, (3) the suspect tried to conceal evidence. The graphical representation thus visualises that the relevant fact (the maid tried to conceal evidence) does not follow directly from the evidence but is the result of a subjective process based on generalisations. The relationship between the evidence and the fact is therefore indirect, which may have an impact on the conviction of the judge.

The third benefit we have found in using a graphical method is that it can help judges to give reasons for the court's decision. The diagramming scheme compels judges to describe the links between the evidence and the facts. It also helps them identify what pieces of evidence support each evidential fact. In addition, the summary list describes all the elements involved in the reasoning in an orderly fashion: evidence, facts, judge's assessments, and generalisations. When writing the decision, the judge can rely on the summary list and the chart to express the reasoning they followed. This makes the judgment writing stage much easier. Our research has also shown that graphical methods can be a real help to judgment writing when the decision in favour of the suspect is based on a lack of evidence. These court decisions are usually difficult to write, as the judge simply finds that there is insufficient evidence of guilt. A diagramming scheme can help the judge to explain the lack of evidence. For instance, the chart can make it clear that reliable evidence is not relevant to prove guilt: in the Lambert case, the DNA analysis did not identify any trace of the victim in the suspect's apartment. The chart may also show that a relevant fact is not supported by any direct evidence: for example, in the Caro case, there was direct evidence that the maid entered 
the victim's room, but there was no direct evidence that she took the watch from the room. The graph makes it possible to precisely identify the weaknesses of the file with regard to relevance, probative force, and the more or less direct link between evidence and a fact. It also makes it possible to visualise all the inferences that contain a high degree of subjectivity (generalisations and assessments by the judge). All these weaknesses can then be emphasised by the judge to justify his or her decision in favour of innocence.

\section{Limitations of diagramming schemes with regard to judicial practices}

The training sessions we conducted in collaboration with the Ecole Nationale de la Magistrature allowed us to gather feedback from judges on the Orderly Method of Evidence Analysis, during debriefings or in evaluation questionnaires. These reactions reflect the feeling that the graphical methods are not adapted to the daily practice of justice. Some of the criticisms we found had already been made by others. Even though Wigmore insisted that the chart method should be 'not too complicated in variety of symbols' (Wigmore, 1913, p. 749), it is nevertheless considered complex and timeconsuming (Twining, 1985, p. 164; Robertson, 1990, p. 211; Anderson, 2007, p. 99; Goodwin, 2000, p. 232; Chalamish, Gabbay, and Schild, 2011, p. 61; McDermott, 2015, p. 527). Beyond this broad observation, we have identified several obstacles to the use of graphical methods by judges in their everyday routine.

A first obstacle arises from the fact that the amount of evidence collected by investigators in criminal cases has increased considerably since Wigmore's time. Today, even in ordinary cases investigators routinely collect evidence that did not exist at the beginning of the twentieth century: information from the contents of cell phones or from telephone operators, images from CCTV cameras, DNA searches, geolocation. This evidence is in addition to traditional evidence (witness statements, expert opinions), so that most cases involve a large amount of evidence. This is further amplified when judges work with written records, which complement the oral proceedings. Working with written files, and not on court records or published judgements, we found that the evidence list could easily contain more than 100 items even in simple cases. Such a situation might justify the use of diagramming schemes more than ever, since they are designed precisely for situations in which there is a large amount of evidence. Yet, perhaps paradoxically, it is these situations that most clearly demonstrate the limitations of graphical methods. It must then be taken into consideration that a judge who wishes to use a graphical method on a routine basis will have to draw up very long lists and make particularly complex graphs to solve everyday cases. The task is impractical.

In the French criminal justice system, this obstacle is all the more significant as half of all cases are brought before a judge without recourse to a negotiated procedure. While common law countries are experiencing a shift in litigation towards negotiated justice (Galanter, 2004, Roach Anleu, and Mack, 2010; Langbein, 2012), the 2019 statistics of the French Ministry of Justice indicate that 611,000 criminal cases resulted 
in a negotiation with the public prosecutor, while 607,000 cases were sent to a judge without negotiation (Chambaz, 2020). Faced with such a large number of cases and subject to the requirements of the efficient administration of justice, it is difficult for judges to implement a method of reasoning that increases the time taken to deal with each case.

\section{Limitations of diagramming schemes with regard to evidential reasoning}

The teaching of graphical methods of evidential reasoning to judges highlights the limitations of these methods not only from a practical point of view, but also from an evidential reasoning theory perspective. While graphical methods aim to give a view of the whole case, our research has found that this objective faces two serious difficulties. On the one hand, the graphical representation does not allow for the integration of the reasoning in its entirety; on the other, the implementation of the method implies choices that expose the reasoning to judgmental biases.

The graphical method is based on the evidence available in the file. Through successive inferences, the evidence leads to the formulation of relevant facts and then decisive facts. Conversely, the method does not allow facts, hypotheses, or reasoning to emerge that are not based on any evidence. For example, in the Lambert case, the knife used to attack the victim was not found. This fact plays an important role in the decision of judges because the absence of the weapon weakens the prosecution's case. However, this absence is not supported by any evidence, so that the graph does not show that the knife was not found. Only intermediate facts are highlighted (e.g. the defendant did not have a weapon in his room). In the Lambert case again, the investigators did not pursue an alternative lead, which was suggested by the testimony of a neighbour who had seen a person leaving the building and getting into a green car parked in the carpark. The lack of research by the police to verify the statements of this witness suggests that the investigation was not comprehensive and casts doubt on the guilt of the suspect. Some of the judges who participated in the training sessions felt that this gap in the investigation should benefit the suspect. The Court of Appeal that decided the case also considered that the presence of a third party reported by the witness had not been sufficiently investigated. The chart allows for the existence of an alternative lead suggesting that the perpetrator could be someone else than Mr Lambert, but does not allow for conclusions to be drawn about the flaws in the investigation. Although the flaws in the investigation were of particular importance in the reasoning followed by the judges, they are not represented in the graph. This applies not only to the facts (the investigation is incomplete) but also to the inferences drawn from them (a doubt remains). Therefore, while the graphical method allowed for a complete representation of the case, it did not allow for a complete representation of the reasoning. As a result, the graphical method has not fully fulfilled its role as a decision support tool.

The method consists of moving from a complex case to a shorter list of decisive facts. Eventually the judge becomes able to decide on the guilt of the suspect by 
considering only the decisive facts, leaving aside the details of the evidence, intermediate facts, or inferences. The identification of the decisive facts is hence central in the process of conviction. However, this pointed to several biases.

A first bias concerned the selection of the decisive facts. In the Lambert case, we presented six facts in favour of the prosecution and only three facts in favour of the defence. In addition, two facts in favour of the defence were tagged with a question mark, which means we considered them doubtful. In the end, the balance was between six decisive facts in favour of the prosecution and one fact in favour of the defence (the lack of motive). Yet, in this case, the Court of Appeal acquitted Mr Lambert based on the benefit of the doubt, and a third of the participants in the training also found him not guilty. Although the method does not involve counting the facts in favour or against the accused, this suggested a gap between the graphical representation of the case and the doubt expressed by some judges. During the debriefing sessions, judges claimed that we had deliberately selected relevant facts in favour of the prosecution and that our graph was hence biased towards the guilt of the suspect. To some judges, the graphical method did not allow for more objective or rigorous evidential reasoning. In particular in the Lambert case, the graph did not allow us to see all the areas of uncertainty that the investigation had not resolved.

A second bias concerned the formulation of the decisive facts. Several criticisms were made of the formulations that we proposed during the training. For example, one of the decisive facts in the Lambert case is whether the victim was injured by a weapon. This fact is certainly decisive: for there to be an offence of violence, the victim must have been injured. In practice, the case presented a wide range of evidence of weapon injury (police findings, testimony from the fire brigade, expert opinion). This abundant evidence led to a very strong conviction (a certainty) that the victim was indeed injured by a weapon. Because of this certainty, several judges considered that the fact was not decisive. On the contrary, in their view, the fact was irrelevant to the evidential reasoning, since there was no doubt about it. It was therefore not necessary to discuss it and even less useful to include it in a chart. This criticism is tantamount to considering that certain facts, which are supported by very solid evidence, have only a very small place in the reasoning because they do not allow the question of guilt to be decided. However, if only the uncertain facts are retained as decisive facts, a new difficulty arises with regard to their formulation. For example, in the Lambert case the key question was whether the suspect was present in the victim's apartment at the time of the attack. This fact was uncertain and the evidence was contradictory. Only the victim had named $\mathrm{Mr}$ Lambert as his attacker and the suspect denied assaulting him. There was no other evidence to decide the issue. We therefore chose to formulate the determining fact more generally: 'the defendant may have been present at the time of the act'. This wording made it possible to introduce new evidence into the reasoning. The geolocation of the suspect's mobile phone and his personal statements indicated that he had moved around during the evening but that he was present in the area of the attack at the time of the offence. His location was therefore consistent with the assault. During the training sessions, the judges criticised the wording chosen. One judge pointed out that 'either he [the suspect] was present or he was not'. In other words, either the suspect's presence 
was proven or the doubt should benefit him. On the contrary, by formulating the decisive fact differently and by using the expression 'may have been present', we purportedly introduced a bias designed to support the prosecution's case. Conversely, had we phrased the fact as "the suspect was at the scene of the crime", the riposte would necessarily have been: "we don't know that".

Thus, despite all the objectivity and rigour of the work we carried out, the choices we made appeared biased to some judges who considered that the innocence thesis should prevail. This seems to be a serious criticism, since the method is intended to help judges to follow an unbiased process of reasoning or at least to identify possible bias in their reasoning. Ultimately, in complex cases, there is no single or right way to formulate the decisive facts. If a fact is totally uncertain, it is not useful to record it as a decisive fact, because uncertainty then impairs reasoning. In that case, one must endeavour to find another fact, close to the uncertain fact. For example, in the Caro case, the fact that the maid took the watch was totally uncertain. By contrast, a close fact, i.e. the maid visited the room several times, tends to indicate that she 'could' have stolen the watch. The choice of the fact to take into account biases the reasoning by adding a fact favourable to the prosecution. The selection of decisive facts thus appears to be structurally subjective and to actively orient the evidential reasoning. If the evidence does not lead to certain guilt, it may lead to an impression of guilt, which will be considered sufficient, or not, depending on the judge's state of mind. The use of a graphical method hardly provides any greater objectivity or even greater rigour to the reasoning in that respect.

\section{Conclusion}

In this paper we have presented research resulting from a collaboration between academic researchers and the Ecole Nationale de la Magistrature, which is responsible for the training of judges in France. This research was intended to overcome the operational difficulties encountered by the use of graphical methods of evidential reasoning. Although this field of research has experienced great advances since the foundational work of Wigmore and its reinvigoration in the 1980s, the complexity of the methods proposed and the difficulties faced by judges in deploying them remain problematic. The main objective was therefore to reflect on the conditions under which graphical methods could be effectively implemented in the courts. The challenge is all the greater in that the conditions under which justice is exercised have changed considerably since Wigmore's era, both in terms of the volume of cases that courts have to settle and the volume and nature of the evidence that is presented before the courts. In such a context, the need for methods to assist evidential reasoning seems stronger than ever; yet, by the same token, judges have less and less time to devote to the implementation of analytical methods.

In an attempt to remove this obstacle, we set up a research protocol that differed in several respects from that in the existing literature. Firstly, we worked on the basis of real procedural files, the same ones that judges work with. To do this, we analysed two 
criminal cases, the Lambert and Caro cases, which have numerous pieces of evidence associated with them and are marked by persistent uncertainties. Thus our evidential reasoning was not reconstructed retrospectively from the motivation of court rulings, but constructed from the documents in the file. Secondly, we worked in the context of training courses for professional judges. Therefore, the issue of the method's practicability was omnipresent for us. For this reason, we developed an Orderly Method of Evidence Analysis which takes up the fundamental principles of Wigmore's chart method but adapts several of its conceptual and graphic elements. Working with judges has allowed us to observe the way in which they appropriate, or resist, the graphical methods of reasoning. Thirdly, for the first time to our knowledge, we have implemented a diagramming scheme in France, a civil law country in which justice is essentially delivered by professional magistrates working as state officials.

This research shows the undeniable benefits of graphic reasoning methods in terms of clarity of reasoning. Moreover, we found that these methods help to improve the motivation underlying the sentences eventually handed down. However, our conclusions are pessimistic regarding the possibility of these methods being integrated into courts on a routine basis in France. Many authors have pointed out that graphical methods are complex and time-consuming, at least when they aim to capture the whole case (macro-analysis). Our research strongly supports this conclusion. But beyond that, we identify a number of additional difficulties. For example, the graph fails to represent the flaws in the investigation, whereas our research shows that magistrates take the quality of the investigation carried out into account to the greatest extent possible when deciding whether there is sufficient evidence in favour of the guilt of the defendant. Similarly, it became clear that the choice and formulation of the decisive facts exposes the reasoning to judgment bias, and thus makes it difficult to use graphical tools to compare the views of several magistrates when they rule as a panel. The complexity of the graphical methods is therefore not sufficient as an explanation for why they have not succeeded in penetrating judicial practice. The difficulties encountered during our research point to new challenges facing graphical reasoning methods at a time when the managerialisation of justice is making the imperative of efficiency more and more central.

Acknowledgment: For their valuable support and assistance, the authors express particular gratitude to Isabelle Monteils, Deputy Director, Head of the Research and Documentation Department of the Ecole Nationale de la Magistrature; Jean-François Beynel, former First President of the Grenoble Court of Appeal; François Touret-deCoucy, magistrate training coordinator in Grenoble; Thierry Deschanels, magistrate training coordinator in Lyon; Anne Camugli, magistrate at the Court of Appeal of Grenoble. This research has greatly benefited from ongoing discussions with Anouk Barberousse, Isabelle Drouet, and Marion Vorms.

Declaration of conflicting interests: The author(s) declare no potential conflicts of interest with respect to the research, authorship, and/or publication of this article. 
Funding: This research benefited from the financial support of the Ecole Nationale de la Magistrature (cooperation agreement Université Grenoble Alpes / ENM 2018-2021) and has received state aid managed by the Agence Nationale de la Recherche as part of the "Investissements d'avenir" programme (ANR-15-IDEX-02).

\section{References:}

Adler, M. (2003). A Socio-Legal Approach to Administrative Justice. Law and Policy, 25(4), 323-352.https://doi.org/10.1111/j.0265-8240.2003.00153.x

Anderson, T. (1999). On Generalizations I: A Preliminary Exploration. South Texas Law Review, 40, 455-481.

Anderson, T. (2007). Visualization tools and argument schemes: a question of standpoint. Law, Probability and Risk, 6, 97-107. https://doi.org/10.1093/lpr/mgm039

Anderson, T., \& Twining, W. (1991). Analysis of Evidence: How to Do Things with Facts Based on Wigmore's Science of Judicial Proof. Northwestern University Press.

Anderson, T., Schum, D. A., \& Twining, W. (2005). Analysis of Evidence. Cambridge University Press.

Bex, F., Prakken, H., Reed, C., \& Walton, D. (2003). Towards a formal account of reasoning about evidence: argumentation schemes and generalisations, A.I. \& Law, 11(2-3), 125-165.https://doi.org/10.1023/B:ARTI.0000046007.11806.9a

Brady, O., Overill, R., \& Keppens, J. (2014). Addressing the Increasing Volume and Variety of Digital Evidence Using an Ontology. 2014 IEEE Joint Intelligence and Security Informatics Conference, 176-183.https://doi.org/10.1109/JISIC.2014.34

Brunet, P., Halpérin, J.-L., Nollez-Goldbach, R. (2015). "Les styles judiciaires » : diversité des approches, nécessité des évolutions. Droit \& Société, 91, 465-471. https://doi.org/10.3917/drs.091.0465

Chalamish, M., Gabbay, D., \& Schild, U. (2011). Intelligent Evaluation of Evidence using Wigmore Diagrams. In ICAIL '11: Proceedings of the 13th International Conference on Artificial Intelligence and Law (pp. 61-65). https://doi.org/10.1145/2018358.2018366

Chalamish, M., Hazoom, M., \& Schild, U. (2013). Semi-Automatic Creation of Wigmore Diagrams. In ICAIL '13, Jun 10-14 2013, Rome, Italy (pp. 181-185). https://doi.org/10.1145/2514601.2514623

Chambaz, C. (2020). Les chiffres-clés de la justice 2020. Ministère de la justice.

Cour de cassation (2012). Rapport annuel. Cour de cassation. 
Damaška, M. R. (1997). Evidence Law Adrift. Yale University Press.

Dawid, Ph., Schum, D. A., \& Hepler A. (2011). Inference Networks: Bayes and Wigmore. In Ph. Dawid, W. Twining, and M. Vasilaki (Eds.), Evidence, Inference and Enquiry (pp. 119-150). Oxford University Press.

Dawson, J. P. (1968). The Oracles of the Law. Ann Arbor: University of Michigan Law School.

Galanter, M. (2004). The Vanishing Trial: An Examination of Trials and Related Matters in Federal and State Courts. Journal of Empirical Legal Studies, 1(3), 459-570. https://doi.org/10.1111/j.1740-1461.2004.00014.X

Gogolin, G. (2010). The Digital Crime Tsunami. Digital Investigation, 7, 3-8. https://doi.org/10.1016/j.diin.2010.07.001

Goodwin, J. (2000). Wigmore's Chart Method. Informal Logic, 20(3), 223-243. https://doi.org/10.22329/il.v20i3.2278

Gordon, T. (2007). Visualizing Carneades Argument Graphs. Law, Probability \& Risk, 6(1-4), 109-117.https://doi.org/10.1093/1pr/mgm026

Gordon, T., Prakken, H., \& Walton, D. (2007). The Carneades model of argument and burden of proof. Artificial Intelligence, 171, 875-896. https://doi.org/10.1016/j.artint.2007.04.010

Hepler, A. B., Dawid, A. P., \& Leucari, V. (2007). Object-oriented graphical representations of complex patterns of evidence. Law, Probability and Risk, 6, 275-293. https://doi.org/10.1093//pr/mgm005

Hodgson, J., \& Roberts, A. (2010). Criminal Process and Prosecution. In P. Cane, \& H. M. Kritzer (Ed.), The Oxford Handbook of Empirical Legal Research (pp. 89-123). Oxford University Press.

Kadane, J. B., \& Schum D. A. (1996). A Probabilistic Analysis of the Sacco and Vanzetti Evidence. John Wiley \& Sons.

Kjærulff, U. B., \& Madsen, A. L. (2008). Bayesian Networks and Influence Diagrams: $A$ Guide to Construction and Analysis. Springer.

Langbein, J. H. (2012). The Demise of Trial in American Civil Procedure: How it Happened, is it Convergence with European Civil Procedure? In C. H. van Rhee and A. Uzelac (Eds.), Truth and Efficacy in Civil Litigation. Fundamental Aspects of Factfinding and Evidence-taking in a Comparative Context. Intersentia, pp. 119-164.

Lasser, M. (2005). Judicial Deliberations: A Comparative Analysis of Judicial Transparency and Legitimacy. Oxford University Press. 
Markesinis, B. (1994). A Matter of Style. Law Quarterly Review, 110, 607-628.

McDermott, Y. (2015). Inferential Reasoning and Proof in International Criminal Trials. Journal of International Criminal Justice, 13, 507-533. https://doi.org/10.1093/jicj/mqv020

Nance, D. A. (2007). The inferential arrow: a comment on interdisciplinary conversation. Law, Probability \& Risk, 6, 87-95.https://doi.org/10.1093/lpr/mgm035

Quick, D., \& Raymond Choo, K.-K. (2014). Impacts of increasing volume of digital forensic data: A survey and future research challenges. Digital Investigation, 11(4), 273-294.https://doi.org/10.1016/j.diin.2014.09.002

Reed C., \& Rowe G. (2004). Araucaria: Software for Argument Analysis, Diagramming and Representation. International Journal of AI Tools, 14(3-4), 961-980. https://doi.org/10.1142/S0218213004001922

Reed C., \& Rowe G. (2007). A pluralist approach to argument diagramming. Law, Probability \& Risk, 6 (1-4), 59-85. https://doi.org/10.1093/lpr/mgm030

Roach Anleu, S., \& Mack, K. (2010), Trial Courts and Adjudication. In P. Cane and H. M. Kritzer (Eds), The Oxford Handbook of Empirical Legal Research (pp. 546-568). Oxford University Press.

Robertson, B. (1990). John Henry Wigmore and Arthur Allan Thomas: An example of Wigmorian analysis. Victoria U. Wellington L. Rev., 20, 181-212.

Rothmayr Allison, C. (2013). Le droit et l'administration de la justice face aux instruments managériaux. Droit \& Société, 84, 275-289. https://doi.org/10.3917/drs.084.0275

Rowe G., \& Reed C. (2006). Translating Wigmore Diagrams. In P. E. Dunne, T. J. M. Bench-Capon (Eds.), Computational Models of Argument (pp. 171-182). IOS Press.

Rowe G., Macagno, F., Reed, C., \& Walton, D. (2006). Araucaria as a Tool for Diagramming Arguments in Teaching and Studying Philosophy. Teaching Philosophy, 29(2), 111-124. https://doi.org/10.5840/teachphil200629217

Schum, D. (1987). Evidence and Inference for the Intelligence Analyst. University Press of America.

Tecuci, G., Marcu, D., Boicu, M., \& Schum, D. A. (2016). Knowledge Engineering. Building Cognitive Assistants for Evidence-Based Reasoning. Cambridge University Press.

Tillers, P., \& Schum, D. A. (1988). Charting New Territory in Judicial Proof: Beyond Wigmore. Cardozo L. Rev., 9, 907-966. 
Tillers, P. (2007). Visualizing Evidence and Inference in Legal Settings. Law, Probability, \& Risk, 6, 1-4.https://doi.org/10.1093/lpr/mgm006

Twining, W (1985). Theories of Evidence: Bentham and Wigmore. Weidenfeld and Nicolson.

Toulmin, S. S. (2003). The Uses of Argument. Cambridge University Press [First published 1958].

van Gelder, T. (2007). The rationale for Rationale ${ }^{\mathrm{TM}}$. Law, Probability and Risk, 6(1-4), 23-42.https://doi.org/10.1093/lpr/mgm032

Vergès, E. (2007). Procès civil, procès pénal: différents et pourtant si semblables. Recueil Dalloz, (21), 1441-1447.

Vergès, E., Vial, G., \& Leclerc, O. (2015). Droit de la preuve. Presses universitaires de France.

Verheij, B. (2000). Dialectical argumentation as a heuristic for courtroom decisionmaking. In P. J. van Koppen, \& N. H. M. Roos (Eds.), Rationality, Information and Progress in Law and Psychology. Liber Amoricum Hans F. Crombag (pp. 203-226). Metajuridica Publications.

Verheij, B. (2005). Virtual Arguments: On the Design of Argument Assistants for lawyers and other Arguers. TMC Asser Press.

Vignaux G. A., \& Robertson, B. (1992). Wigmore Diagrams and Bayes Networks. In A. Mohammad-Djafari and G. Demoment (Eds.), Maximum Entropy and Bayesian Methods (pp. 93-98). Springer

Walton, D. (2005). Argumentation Methods for Artificial Intelligence in Law. Springer.

Walton, D., Reed, C., \& Macagno, F. (2008). Argumentation Schemes. Cambridge University Press.

Walton, D. (2009). Argument Visualization Tools for Corroborative Evidence, Proceedings of the 2nd International Conference on Evidence Law and Forensic Science, Institute of Evidence Law and Forensic Science, Beijing, 2009, 32-49.

Wigmore J. H. (1913). The Principles of Judicial Proof as Given by Logic, Psychology, and General Experience and Illustrated in Judicial Trials. Little, Brown, and company.

Wigmore J. H. (1937). The Science of Judicial Proof. Little, Brown, and company. 3rd ed. 